\title{
LA ZONA ECONÓMICA EXCLUSIVA Y EL NUEVO ORDEN ECONÓMICO INTERNACIONAL
}

Jorge Castañeda

Las Naciones Unidas han venido adoptando desde hace más de dos décadas un gran número de postulados y objetivos y aun, en ciertas ocasiones, de principios y normas jurídicas, que en su conjunto integran lo que se ha dado en Ilamar el nuevo orden económico internacional.

Los dos principios esenciales de ese nuevo orden son el deber jurídico de cooperación internacional en favor de los países en desarrollo y el principio de la soberanía permanente de los Estados sobre sus recursos naturales. Aunque aparentemente de signo contrario, ambos principios se complementan y refuerzan mutuamente. ${ }^{1}$ El primero está aún lejos de realizarse en la práctica, e incluso de consolidarse jurídicamente. El segundo goza ya de innegable vida jurídica, pero en el terreno de los hechos tiene sólo vigencia limitada. El nuevo orden económico internacional tardará todavía un largo tiempo en convertirse en realidad.

La reglamentación racional del uso del mar y sus recursos puede contribuir de manera importante a darle substancia y operatividad al nuevo orden económico internacional. Ello se debe a una razón específica, no común a otros campos de acción del hombre: el mar, su suelo y subsuelo, y los enormes recursos que contienen, son en su mayor parte de común aprovechamiento para todos. Sin entrar en una discusión académica respecto de si los recursos del mar, o los de su suelo y subsuelo, son res nullius o res communis, baste decir que son de común aprovechamiento. No surge aquí el problema insoluble de pretender una redistribución de recursos que conforme a las concepciones políticas que nos rigen desde hace alrededor de medio milenio, están sujetos a la soberanía de los estados nacionales. Una enorme porción del mar y sus recursos no está sujeta a soberanía o a apropiación de ningún estado. Es un bien común de la humanidad. Esto permite utilizarlo con el fin de corregir, en alguna medida, las desigualdades de la geografía terrestre; permite, al menos idealmente, una distribución más justa de recursos que son comunes, a efecto de avanzar en la consecución

1 Estos dos principios están enunciados, tanto de manera general como en diversas formas de aplicación concreta, en la Carta de Derechos y Deberes Económicos de los Estados, sin duda la expresión más autorizada hasta ahora del nuevo orden económico internacional. 
del ideal que las Naciones Unidas han postulado: colmar en lo posible el abismo que separa en la realidad a pueblos que son iguales en derechos.

¿Cómo y en qué medida el derecho del mar emergente que se ha venido elaborando en las Naciones Unidas desde hace casi diez $\operatorname{años}^{2}$ ha contribuido a ese ideal? Es difícil llegar a una conclusión unánime. Hay, desde luego, opiniones opuestas. Según algunos, los resultados que hasta ahora conocemos tienden a empeorar la situación que existía antes, porque, según se dice, la zona económica exclusiva que es el resultado más conspicuo del nuevo derecho del mar, favorece más bien a los estados industriales y ricos. Dentro del mismo orden de ideas, algunos piensan que el régimen que probablemente se establecerá para la explotación de los recursos minerales de los fondos marinos tampoco ofrece perspectivas halagüeñas para los países atrasados. Acaso tienda a una concentración mayor de recursos minerales muy valiosos en manos de los pocos países con capacidad financiera y tecnológica para extraerlos. Sin embargo, parecería paradójico, si esas opiniones son correctas, que hayan sido precisamente los países en desarrollo los que promovieron la creación de zonas económicas exclusivas y de un régimen para los fondos marinos.

Para llegar a alguna conclusión objetiva hace falta examinar lo que ha ocurrido en esas dos áreas fundamentales: primero, ver qué resultados probables tendrá el establecimiento de zonas económicas exclusivas; y segundo, examinar el impacto posible que el régimen de los fondos marinos pudiera tener en la distribución más justa de los recursos minerales del subsuelo marítimo, aunque hasta estos momentos todavía no se han terminado de negociar algunos elementos esenciales de ese régimen. Por esta última razón, y en vista también de la vastedad del tema, en este artículo se examinará sólo el primer problema.

2 Se entiende aquí por "derecho de mar emergente" el conjunto de disposiciones que se han venido incorporando paulatinamente en los sucesivos textos informales para fines de negociación que han surgido de la Tercera Conferencia de las Naciones Unidas sobre el Derecho del Mar. Ésta se inició en 1974, en Caracas, sin contar con un documento de base, esto es, de un proyecto de convención, ya que el amplio Comité Preparatorio de la Conferencia no logró elaborarlo en tres años de trabajo (6 sesiones), debido a la vastedad y complejidad de los temas y a los intereses encontrados. En ausencia de un documento de base, la Conferencia identificó primero en 1974 las tendencias dominantes y las sesiones ulteriores encargó a los Presidentes de las Comisiones Plenarias la formulación de aquellos textos que en su opinión fueran susceptibles de lograr en mayor grado un consenso generalizado. El último de ellos, llamado Texto Integrado Oficioso para Fines de Negociación (doc. A/CONF. 62/WP. 10), es ya la cuarta versión. Recoge en más de 300 artículos y varios anexos los resultados de ocho años de esfuerzo colectivo. Si bien tiene aún un carácter oficioso y no es un texto aprobado o propiamente negociado, sino una base de negociación, goza de gran autoridad $\mathrm{y}$, salvo en lo que toca al régimen de los fondos masivos, en todas las numerosas otras materias representa un punto de equilibrio y convergencia entre las diversas tendencias de los principales grupos de estados. 


\section{Papel del estado y de los juristas en la creación del nuevo derecho del mar}

Antes de examinar esa cuestión, sin embargo, valdría la pena hacer algunas observaciones acerca de la forma en que históricamente se han llevado a cabo los grandes cambios en las instituciones y principios jurídicos internacionales. Estos cambios nunca -o casi nunca- han ocurrido en la historia como resultado de algún plan global inventado por algún hombre de genio, que haya sido aceptado por la comunidad de naciones por su bondad intrínseca en un momento dado, o en un acto aislado. Las nuevas concepciones políticas y económicas internacionales que han tenido mayor influencia en los destinos de la humanidad siempre han sido el resultado de un proceso de acomodación, de conciliación, de los intereses de los Estados, generalmente en un largo periodo y después de numerosos intentos parcialmente frustrados. Estos procesos se llevan a cabo por etapas sucesivas, cuyos resultados siempre son parciales e imperfectos. Pero cuando se miran estos procesos con perspectiva histórica se advierte que cada una de esas etapas representa un jalón adelante.

En última instancia, esto equivale a decir que los verdaderos autores del derecho internacional, del orden normativo que nos rige, siempre son los Estados y no los juristas. A pesar de que algunos principios de enorme importancia están asociados históricamente a los nombres de algunos individuos, como el principio del mare liberum lo está al de Grocio y el del mare clausum al de Selden, recuérdese que las concepciones del primero no eran sino una expresión de los intereses de Holanda en el siglo xvn en la existencia de mares y comercio abiertos, mientras que las del segundo representaban los intereses opuestos de Inglaterra.

El reconocer estos hechos evidentes no significa, por supuesto, que en el nuevo derecho del mar no tengan cabida las tesis intrínsecamente justas ni, menos aún, las concepciones que reflejan los intereses de la comunidad internacional en su conjunto. En la creación de este nuevo derecho ha habido también una interacción fértil entre las concepciones idealistas de los individuos y los intereses de los estados. En gran medida, lo que dio origen en 1967 a la acción de las Naciones Unidas para reformar el derecho del mar fueron las célebres propuestas del Representante de Malta, Arvid Pardo, para declarar "patrimonio común de la humanidad" los fondos marinos, las cuales reflejan en mayor grado las concepciones individuales de su autor que los intereses limitados de su país. En la Conferencia de las Naciones Unidas sobre el Derecho del Mar también participa activamente el mundo académico, a través de numerosas organizaciones no gubernamentales, y algunos de sus planteamientos han sido tomados en cuenta.

Pero no debemos caer en el error de suponer que una especie de esquema global y sistemático, que un plan maestro, teóricamente válido e intrínsecamente valioso, debe necesariamente presidir e inspirar los debates en las conferencias internacionales que buscan regular los usos del mar. Sobre 
todo, no debe caerse en el desaliento si en ese largo proceso no se van cumpliendo las previsiones de lo que se estima una concepción ideal. La filosofía de lo óptimo o nada no es realista, ni históricamente fundada, ni eficaz. Los estados no siempre son consistentes, rara vez son altruistas, pero querrámoslo o no, son los autores insustituibles del derecho internacional.

Los intereses de la comunidad de naciones en su conjunto tal vez sean apreciados en mayor grado por juristas no comprometidos que por representantes de gobiernos, quienes por razón natural suelen defender los intereses limitados y a veces estrechos de sus países. El pensamiento independiente y crítico es indispensable en la creación de todo orden normativo. Pero sólo si se le conjuga con una visión prudente y realista de la sociedad internacional contemporánea, con su acentuada heterogeneidad, sus imperfecciones y sus carencias, será posible juzgar objetivamente el enorme esfuerzo colectivo que ha significado crear un nuevo derecho del mar, y evaluar su impacto sobre el nuevo orden económico internacional.

\section{Orígenes de la zoma económica exclusiva}

Recordemos cómo surgió el concepto de la zona económica exclusiva. Los países en desarrollo que inicialmente lo postularon perseguían como objetivo el modificar en alguna medida el sistema prevaleciente en la distribución internacional de la riqueza. Sus esfuerzos por reservar a los estados costeros los recursos próximos a sus costas no son, en definitiva, sino otro aspecto de esa larga y penosa lucha que libran en todos los frentes para asegurar, y en ocasiones para reivindicar, su soberanía permanente sobre los recursos naturales.

Claro está que el principio básico del derecho del mar tradicional, la libertad de los mares, no fue inventado desde hace tres siglos por las potencias marítimas y pesqueras con el propósito deliberado de explotar a las pequeñas, y menos aún a los numerosos estados que aún no habían alcanzado su independencia. Pero lo cierto es que los estados más atrasados, que aspiran hoy a explotar plenamente en su beneficio los recursos del mar próximos a sus costas, sí se ven impedidos de hacerlo por la existencia de obstáculos y situaciones amparadas por el principio de la libertad de los mares entendido en su forma clásica, es decir, como la libertad de explotar en forma irrestricta y aun abusiva esos recursos sin tener responsabilidad frente a nadie, ya que esos recursos eran considerados como libres para el primero que los ocupara. La libertad de pesca favoreció de hecho a las grandes potencias en detrimento de las pequeñas. Por ello, ante el creciente aumento en el consumo de los productos marinos y en vista de su carácter cada vez más limitado, se ha vuelto indispensable sustituir en alguna medida ese concepto tradicional por el de una libertad de los mares responsable, por el de una libertad de aprovechar con mesura las riquezas que no pertenecen sólo a los estados que tienen el poder suficiente para excluir a los demás de su explotación. 
Ante esa nueva situación que gradualmente venía perfilándose desde hace tres décadas, ¿ cuál fue la respuesta que los distintos estados han dado al problema?

La primera y más obvia fue la pretensión de ampliar las zonas sujetas a la jurisdicción y control del estado costero. Los tres estados latinoamericanos del Pacífico Sur, desde la década de los cuarenta, estimaron que las riquezas pesqueras cercanas a sus litorales deberían estar reservadas al estado ribereño, en igual forma que lo están los recursos minerales de su pla taforma continental. La presencia de los recursos vivos está en estrecha dependencia física y biológica del medio costero. Estos países consideraban pues, que existe un elemento de justicia en considerarlos como una parte de los recursos del estado costero.

Al iniciarse esta corriente, algunos estados tendieron a ampliar su mar territorial, esto es, la banda de mar sobre la que ejercen soberanía plena, hasta 200 millas. $^{3}$ Con el tiempo, otros estados que perseguían el mismo objetivo de reservar a sus nacionales los recursos naturales dentro de su zona, consideraron que era aquélla una solución desmedida, que podía tener el efecto de entorpecer o limitar las libertades tradicionales de navegación, sobrevuelo y otras. No había necesidad real de reconocerle al estado costero esa capacidad legal mediante la atribución de soberanía, ya que bastaba con el reconocimiento de derechos soberanos, no sobre el área misma, sino sobre los recursos que se encontraran en la misma, para fines de su explotación. Ese fue el origen de la tesis del mar patrimonial, que pronto cambió su denominación por la de zona económica exclusiva.

Ciertamente, en teoría había otra respuesta, tal vez más conforme a una concepción ideal: establecer una administración global, a escala universal, de los usos del mar y de sus recursos, fuera del mar territorial, mediante un complejo sistema de instituciones y mecanismos. Pero hay que preguntarse con realismo y sinceridad si la comunidad internacional está preparada hoy en día para establecer un sistema semejante. Por cierto, los obstáculos mayores para ello no habrían de provenir necesariamente de los países en desarrollo. Tampoco las grandes potencias pesqueras estarían dispuestas a abandonar el viejo principio de la libertad de captura y substituirlo por otro que necesariamente implicaría reconocer que esos recursos

3 Aunque empleando distintas figuras, instrumentos y regímenes juridicos - lo cual ha producido confusión en ciertos casos respecto de la naturaleza jurídica del régimen reivindicado- los siguientes estados latinoamericanos han proclamado un mar territorial de 200 millas: Ecuador, Perú, Brasil, Uruguay, El Salvador, Nicaragua y Panamá. Por su parte, Argentina reivindicó soberanía sobre las aguas que cubren la plataforma continental, y Chile estableció una zona jurisdiccional de 200 millas aunque manteniendo un mar territorial de 3 millas. A escala universal, la tendencia a ampliar el mar territorial hasta 200 millas no prosperó, como en un principio pudo suponerse; incluso, algunos de los pocos estados "territorialistas" se han sumado de hecho a la corriente alternativa que culminó en el establecimiento de la zona económica exclusiva. 
no son del primer ocupante, sino de todos, y que, por tanto, se requeriría una autorización, dentro de un sistema internacional global, para explotarlos racional y justamente en beneficio de todos. Sin duda éste habría sido el obstáculo principal. La mejor prueba es que, tocante a los minerales que yacen en los fondos marinos, a pesar de que aún no han sido explotados comercialmente, de que no hay tanta urgencia en explotarlos como los recursos vivos, y de que las Naciones Unidas los han declarado "patrimonio común de la humanidad", las grandes potencias, a pesar de ello, prefieren un sistema de acceso libre a esos recursos minerales, mediante un mero régimen de licencia, y no una verdadera administración internacional.

Los países en desarrollo ven con preocupación esos obstáculos para establecer un sistema internacional, racional y justo, para la explotación de esos minerales. Difícilmente podrían esperar, por tanto, que se estableciera un sistema semejante en lo que hace a los recursos vivos del mar, que tomara en cuenta sus intereses. De ahí su explicable preferencia por controlar ellos mismos los recursos próximos a sus costas. La realidad política internacional, los intereses nacionales, se oponen a lo que parecería ser el plan ideal, acaso el más racional. Esto es lamentable, pero es la realidad.

\section{Zonas económicas y distribución real de los recursos vivos}

Cabe preguntarse ahora en qué forma el establecimiento de la zona económica exclusiva ha contribuido, o podría contribuir, a una distribución más justa de los recursos ictiológicos. Se dice que las zonas económicas exclusivas han beneficiado, sobre todo, a las grandes potencias con costas extensas. Creo que aquí se sufre de una impresión errónea, de una confusión. Hay una visión deformada de la realidad que proviene, en parte, de la representación puramente visual en los mapas de las zonas económicas. Se tiende a ver el problema como si antes existieran zonas abiertas, libres, que beneficiaban a países en desarrollo, y que ahora les están vedadas por el establecimiento de zonas económicas por parte de las grandes potencias con costas extensas.

En realidad, las zonas económicas exclusivas sí benefician realmente a una gran mayoría de países en desarrollo. Antes, todo el mar libre estaba teóricamente abierto a todos los países, incluyendo las áreas que hoy son zonas económicas establecidas por las grandes potencias. Pero en la realidad de las cosas, esas áreas no representaban beneficio alguno para los países en desarrollo, al no poderlas utilizar por carecer de los capitales, flotas y tecnología que les permitieran alejarse de sus propias costas, e ir a pescar, a veces a grandes distancias, en las zonas económicas de los países desarrollados. La creación de estas áreas por los países avanzados es casi indiferente para la mayoría de los países en desarrollo. El mar libre era para ellos una ilusión. Era un derecho meramente legal (si se permite el pleonasmo'), un derecho formal sin substancia real. 
Pero a cambio de ese derecho teórico que no significaba nada, tenían que pagar un precio, en vista del principio de la libertad de captura. Tenían que tolerar que las grandes potencias a su vez pescaran libremente en los mares próximos a las costas de los países en desarrollo. Y esto sí era una realidad. Las grandes potencias sí pescaban a menudo en gran escala en esas zonas, con la consecuencia de que entorpecían así, y a veces imposibilitaban, el desarrollo de una industria pesquera nacional en los países más atrasados, aparte de que su explotación, en ocasiones abusiva, ponía esos recursos en peligro de extinción. El resultado neto era una injusta distribución internacional del trabajo. Para unos, la pesca industrial; para otros, la artesanal. Todavía en los años de 1968 y 1969, cuando los Estados Unidos y la Unión Soviética llevaron a cabo amplias consultas paralelas con numerosos países sobre la posibilidad de convocar una nueva conferencia del mar que revisara el régimen que surgió de las Convenciones de Ginebra de 1958, esos estados proponían en sus sugestiones iniciales que se otorgara a los países costeros un derecho preferencial sobre los recursos del mar hasta 200 millas de sus costas, respecto de lo que pudieran pescar mediante embarcaciones hasta de 300 toneladas, quedando el resto libre para ser capturado por cualquier país, sin el pago de ningún derecho. La aceptación de ese plan hubiera significado condenar a los países costeros en desarrollo a una pesca puramente artesanal por toda la eternidad.

Desde entonces ha habido avances considerables. Tal y como están formuladas las disposiciones del derecho del mar emergente en el Texto Integrado Oficioso para Fines de Negociación ${ }^{4}$ que ha surgido de la sexta sesión

4 Las disposiciones básicas relativas a la zona económica exclusiva están contenidas en los siguientes artículos:

Artículo 56. Derechos, jurisdicción y obligaciones del Estado ribereño en la zona económica exclusiva.

1. En la zona económica exclusiva, el Estado ribereño tendrá:

a) Derechos de soberanía para los fines de exploración, explotación, conservación y administración de los recursos naturales, tanto vivos como no vivos, del lecho y el subsuelo del mar y las aguas suprayacentes, y con respecto a otras actividades con miras a la exploración y explotación económicas de la zona, como la producción de energía derivada del agua, de las corrientes y de los vientos;

b) Jurisdicción, con arreglo a las disposiciones pertinentes de la presente Convención, con respecto a:

i) El establecimiento y la utilización de islas artificiales, instalaciones y estructuras;

ii) La investigación científica marina;

iii) La preservación del medio marino;

c) Otros derechos y obligaciones previstos en la presente Convención.

2. En el ejercicio de sus derechos y en el cumplimiento de sus obligaciones, en la zona económica exclusiva, con arreglo a la presente Convención, el Estado ribereño tendrá debidamente en cuenta los derechos y obligaciones de los demás Estados y actuará de una manera compatible con las disposiciones de la presente Convención. 
de la Conferencia de las Naciones Unidas (1977), los países en desarrollo sí tienen una posibilidad real de desarrollar su industria pesquera y de participar en mayor grado que antes en el aprovechamiento de esos recursos.

Un ejemplo revelador, que pone de manifiesto los beneficios para los países en desarrollo que establecen zonas económicas, se refiere a México. Con base en el acuerdo implícito que se desprende de los debates y conclusiones a los que ha llegado la Conferencia de las Naciones Unidas, conclusiones incorporadas ya en 1975 en lo que entonces se llamaba Texto Único para Fines de Negociación, México consideró que no actuaría en violación del derecho internacional al establecer unilateralmente una zona económica exclusiva de 200 millas a lo largo de sus costas. Esto se llevó a cabo a fines de 1975. Desde entonces, 62 países, número que representa sin duda una mayoría de estados costeros, han creado unilateralmente zonas semejantes. Con base en la Ley que proclamó México sobre la zona económica exclusiva se llevaron a cabo negociaciones en 1976 tanto con Cuba como con Estados Unidos, países que habían venido pescando tradicionalmente camarón en el Golfo de México en lo que ahora es la zona económica mexicana. Una parte apreciable del rendimiento de la pesquería de camarón era explotado por esos dos países. Ello había impedido una expansión de la industria pesquera mexicana del camarón, debido a la competencia que

3. Los derechos enunciados en el presente artículo con respecto al lecho y el subsuelo del mar se ejercerán de conformidad con la parte VI de la presente Convención.

Artículo 57. Anchura de la zona económica exclusiva.

La zona económica exclusiva no se extenderá más allá de las 200 millas marinas medidas a partir de las líneas de base desde las cuales se mide la anchura del mar territorial.

Artículo 58. Derechos y obligaciones de otros Estados en la zona económica exclusiva.

1. En Ia zona económica exclusiva, todos los Estados, tanto ribereños como sin litoral, gozarán, con sujeción a las disposiciones pertinentes de la presente Convención; de las libertades a las que se refiere el artículo 87 de navegación y sobrevuelo y del tendido de cables y tuberías submarinos, y de otros usos del mar internacionalmente legítimos relacionados con dichas libertades, como los vinculados al funcionamiento de naves, aeronaves y cables y tuberías submarinos, y que sean compatibles con las demás disposiciones de la presente Convención.

2. Los artículos 88 a 115 y otras normas pertinentes del derecho internacional se aplican a la zona económica exclusiva en la medida en que no son incompatibles con esta parte.

3. En el ejercicio de sus derechos y en el cumplimiento de sus obligaciones en la zona económica exclusiva, con arreglo a la presente Convención, los Estados tendrán debidamente en cuenta los derechos y obligaciones del Estado ribereño y cumplirán las leyes y reglamentos establecidos por el Estado ribereño de conformidad con las disposiciones de la presente Convención y otras normas del derecho internacional en la medida en que no sean incompatibles con esta parte. 
significaban las flotas extranjeras. Se convino en dichos tratados en que la pesca de camarón de uno y otro país se reduciría el primer año en un 40 por ciento respecto de lo capturado el año anterior, o sea, 1975, y en que las capturas se reducirían gradualmente hasta terminar totalmente a fines de 1979. En otros términos, México estuvo dispuesto a permitir la pesca del excedente por esos países durante un periodo temporal. Además de fomentar el desarrollo de la flota mexicana, estos acuerdos significaron para el país un beneficio económico, ya que se obtuvo por concepto de derechos, por permitir la pesca de excedentes que no podíamos pescar, más de un millón de dólares por el primer año, por cada uno de esos países.

Este ejemplo también pone de relieve otro hecho. Además de los beneficios para el estado costero, el establecimiento de la zona económica significó un aprovechamiento más racional de los productos del mar. En adelante, el camarón será explotado por el país que está más cerca del recurso, con mayor economía en combustible y en tiempo y esfuerzo invertidos. Obviamente, un efecto semejante no podrá producirse siempre. Pero en la medida en que estos casos se multipliquen, la explotación de los recursos vivos del mar será más racional y eficiente, además de contribuir a una división internacional del trabajo más justa.

\section{Características de la zona económica exclusiva y su contribución al nuevo orden económico internacional}

El régimen de la zona económica debe tener tres características si ha de contribuir a un orden económico internacional más justo: 1) no tener por efecto el abatir la producción mundial de alimentos; 2) preservar el equilibrio entre los derechos del estado costero y los demás estados, sobre todo en términos de no desquiciar el ejercicio de otras libertades, y 3) no excluir a ningún grupo de países de la posibilidad de aprovechar también los recursos del mar, aunque carezcan de costas.

Como se dijo, conforme al régimen de la zona económica exclusiva se reconocen derechos soberanos a los estados costeros sobre los recursos vivos, pero al propio tiempo se consagra el principio de la óptima utilización de los recursos. Es obvio que el estado costero no puede impedir la pesca por otros estados cuando él mismo no puede aprovecharla íntegramente. En época de crisis alimentaria, o aun en cualquier época, sería contrario a los intereses de la humanidad que los recursos ictiológicos se perdieran para todos por falta de aprovechamiento, dado el carácter renovable de estos recursos. Por ello, el Texto Integrado establece y consagra el principio llamado de "la óptima utilización de los recursos" (artículo 62). Los demás estados tendrán derecho a explotar los excedentes. Pero al propio tiempo, el estado costero, que ejerce derechos soberanos sobre la totalidad y no sólo sobre una parte de los recursos, obtendrá algún beneficio económico por la explotación de terceros. 
$\mathrm{El}$ régimen que se desprende del Texto Integrado es un régimen equilibrado en lo que toca a los derechos del estado costero y los demás estados. A la vez que se reconocen al estado ribereño derechos soberanos sobre los recursos renovables y no renovables hasta 200 millas, así como ciertas jurisdicciones en materia de la prevención de la contaminación de los mares y de la investigación científica en esa zona, se consagran en forma categórica las libertades de navegación, sobrevuelo y tendido de cables y tuberías sumbarinos para todos los demás estados de la comunidad internącional. El régimen de la zona comprende así elementos que pertenecen tradicionalmente a la alta mar y elementos propios del mar territorial. Esta coexistencia de derechos, jurisdicciones y libertades de los estados costeros y de los demás estados le dan a la zona económica exclusiva un status internacional especial.

\section{El problema de la naturaleza juridica de la zona económica exclusiva}

Durante varios años se discutió en la Conferencia de las Naciones Unidas y en su Comisión Preparatoria la cuestión de la naturaleza jurídica de la zona económica exclusiva. Algunos mantenían y siguen manteniendo que debía ser una especie de mar territorial con excepciones claramente reconocidas a favor de los terceros estados en lo que se refiere a las libertades tradicionales de navegación, sobrevuelo y otras. Otros países y juristas, por el contrario, sostenían y siguen sosteniendo que se trata de una zona de alta mar en la que se consagran excepcionalmente ciertos derechos o jurisdicciones en favor del estado costero, en materia de pesca y parcialmente en lo que toca a investigación científica y prevención de la contaminación. El problema no pudo resolverse ni en uno ni en otro sentido. La insistencia en una $u$ otra tesis habría impedido totalmente un acuerdo en esta materia y, quizá, habría obstaculizado un acuerdo global en la Conferencia. Finalmente, después de varios años, y en buena medida gracias a la insistencia de México, se tuvo que llegar a la conclusión inevitable de que la zona económica exclusiva no era ni alta mar con excepciones a favor del estado costero, ni mar territorial con excepciones a favor de los demás estados. Se trata de una zona con un estatuto internacional propio. Fue creada para dar satisfacción a intereses y necesidades nuevas y no puede asimilarse a ninguna de las dos categorías tradicionales del derecho del mar.

Debido a las objeciones de algunas potencias marítimas, sobre todo la Unión Soviética, que sigue insistiendo en que la zona económica exclusiva debe ser considerada como alta mar con ciertas excepciones específicas y limitadas en favor del estado costero, no fue posible sino hasta 1977 consagrar la tesis de la zona económica como área sui generis, con un estatuto específico y propio. Finalmente, y como resultado de negociaciones en el seno de un grupo informal de 16 países, cuyos resultados fueron amplia 
pero no unánimemente aceptados, se logró la incorporación en el Texto Integrado de Negociación del nuevo artículo 55, propuesto por México, cuyo texto es el siguiente:

\section{Artículo 55. Régimen jurídico específico de la zona económica exclusiva}

La zona económica exclusiva es una zona situada fuera del mar territorial y adyacente a éste, sujeta al régimen jurídico específico establecido en esta parte, de acuerdo con el cual los derechos y jurisdicciones del Estado ribereño y los derechos y libertades de los demás Estados se regirán por las disposiciones pertinentes de la presente Convención. ${ }^{\overline{5}}$

\section{El problema de los derechos residuales}

La cuestión de la naturaleza jurídica de la zona económica tiene que ver con el problema de los llamados derechos residuales. Es lógico que en el futuro puedan surgir nuevos usos, ahora imprevistos, de los mares. También es natural prever que en el aprovechamiento del mar y sus recursos en la

5 La Unión Soviética sólo aceptó parcialmente los acuerdos informales que surgieron de dicho grupo. Insiste en que se añada al artículo 55 un segundo párrafo en el sentido de que: "Ningún Estado podrá pretender legítimamente someter a su soberanía parte alguna de la zona económica". Si bien la gran mayoría de Estados del poderoso Grupo de Estados Costeros en la Conferencia, que cuenta con cerca de 80 miembros y es presidido por México, no se oponen al concepto mismo propuesto por la Unión Soviética, estiman que la introducción de ese segundo párrafo alteraría el delicado equilibrio de disposiciones relacionadas con los poderes del estado costero y de los demás estados dentro de la zona económica exclusiva, que han sido negociadas con tanta dificultad. Por ello, y dando así una elocuente e impresionante demostración de la fuerza del Grupo, los estados costeros dieron respuesta a ese intento de alterar el "paquete" negociado, presentando una contra-propuesta suscrita en menos de cuatro horas por 50 países. Esta contra-propuesta, que revivía una sugestión hecha ante el aludido grupo negociador de 16 países y que no había sido aceptada por las potencias marítimas, decía así: "La zona económica exclusiva no forma parte de la alta mar ni del mar territorial". Este concepto se desprende jurídicamente del artículo 55 citado, leído en relación con el artículo 86, el cual establece que "Las disposiciones de esta parte (alta mar) se aplicarán a todas las partes del mar no incluidas en la zona económica exclusiva, en el mar territorial o en las aguas interiores de un Estado.... Con objeto de facilitar la aceptación del artículo 86 por las potencias marítimas, los estados costeros (con la excepción de pocos estados "territorialistas") estuvieron dispuestos a aceptar una formulación que pone mayor énfasis en el aspecto funcional (aplicabilidad de normas) que en el puramente geográfico. Las dos propuestas aludidas - la de la Unión Soviética y la de 50 estados costeros- no han sido objeto de pronunciamiento oficial por la Conferencia y no parece probable que el texto del actual Texto Integrado sea modificado en ese aspecto en un sentido o en otro. 
zona económica puedan presentarse conflictos entre los derechos del estado costero y los de los demás estados, ya que ambos grupos de derechos coexisten en la zona. Si se la caracterizara básicamente, sea como alta mar o como mar territorial, esta caracterización prejuzgaría conceptualmente sobre la solución de esos conflictos. Los "derechos residuales", es decir, los derechos no estrictamente atribuidos en la Convención, se adjudicarían en caso de conflicto, sea a los demás estados o al ribereño, según que la zona hubiera sido reconocida como altamar o como mar territorial. Como no podía haber acuerdo en la Conferencia sobre esa caracterización ni, por tanto, sobre la adjudicación de los derechos residuales, era indispensable dar alguna guía o directiva general para la solución de esas controversias previsibles.

Ése es el sentido del importante artículo 59 del Texto Integrado, el cual parte de la premisa de que se trata de una zona sui generis. Ahí se establece $-\mathrm{y}$ por cierto, el texto del artículo 59 fue una de las más importantes propuestas presentadas por México- que en caso de que algún derecho o jurisdicción no hubieran sido claramente atribuidos por la Convención misma al estado costero o a los otros estados, y de que surgieran conflictos entre derechos concedidos al estado costero o a los demás, estos conflictos deben resolverse sobre la base de la equidad. ${ }^{6}$

No se puede dar una respuesta única a las disputas que contempla el artículo 59. No habrá en la Convención una regla general en el sentido de que las que deben prevalecer, en principio, sean los derechos del estado costero o bien los de terceros estados. Prevalecerá, conforme a la equidad, el derecho que parezca tener más peso en el caso concreto, atentós los intereses de toda la comunidad internacional y de los estados interesados.

\section{Acceso a la zona económica de los estados sin litoral o geográficamente desaventajados}

Otro elemento importante que contribuye al equilibrio del régimen de la zona económica exclusiva es el relativo a la participación de los estados sin litoral y de los estados con características geográficas especiales en la explotación de los recursos vivos.

Esos estados, que por sus características geográficas no pueden establecer o derivar beneficios del establecimiento de una zona económica exclusiva

16 El artículo 59 dispone lo siguiente:

En los casos en que la presente Convención no atribuya derechos o jurisdicción al Estado ribereño o a otros Estados en la zona económica exclusiva, y surja un conflicto entre los intereses del Estado ribereño y los de cualquier otro Estado o Estados, el conflicto debería ser resuelto sobre una base de equidad y a la luz de todas las circunstancias pertinentes, teniendo en cuenta la importancia respectiva que revistan los intereses de que se trate para las partes, así como para la comunidad internacional en conjunto. 
propia no deben ser excluidos del acceso a los recursos vivos. Ese acceso, sin embargo, no debe tampoco perjudicar en exceso los intereses de los estados costeros.

Después de largas y difíciles negociaciones durante las últimas cinco sesiones de la Conferencia, se llegó en 1978 a una fórmula que representa un verdadero equilibrio entre los intereses en juego. Los principales elementos de la nueva disposición, que cuenta con un apoyo muy generalizado, ${ }^{7}$ son los siguientes: reconocimiento de un derecho a participar en la explotación de los recursos vivos de las zonas económicas exclusivas de los Estados ribereños de la misma subregión o región; participación limitada a la explotación de sólo una parte apropiada del excedente de esos recursos vivos, sobre una base equitativa; consideración de los factores económicos y geográficos pertinentes de todos los estados interesados en la determinación de la parte apropiada del excedente; establecimiento de las condiciones y modalidades de la participación mediante acuerdos bilaterales, subregionales o regionales negociados con el estado costero.

No es superfluo subrayar que en la fórmula de compromiso aludida no se reconoce derecho alguno a los Estados sin litoral ni a los estados con características geográficas especiales con respecto a la explotación de los recursos minerales de las zonas económicas exclusivas en cuestión.

\section{La zona económica exclusiva y la cooperación internacional}

El aprovechamiento más racional y justo de los mares no sólo se logra mediante la, consagración de normas permisivas o prohibitivas. Ésta es sólo una primera etapa. Obviamente, el objeto específico y principal de la futura convención general sobre el derecho del mar es el de delimitar las áreas marítimas y establecer un sistema de competencia, de derechos y obligaciones, en esas áreas. Los ecólogos y conservacionistas se quejan de que no se han provisto disposiciones adecuadas para proteger el medio ambiente oceánico en general, o ciertas especies en peligro de extinción ni, menos aún, medidas para aumentar la productividad de los recursos vivos. Esto es cierto, pero tales cuestiones serán materia de otras convenciones futuras, una vez que culmine la primera tarea. Del mismo modo, otra empresa futura consistirá en reforzar considerablemente la cooperación internacional. Estos aspectos positivos del aprovechamiento de mar y sus recursos son los que en definitiva contribuirán en mayor grado al nuevo orden económico internacional. Así, la utilización de los recursos de la zona económica exclusiva debería dar lugar a un nuevo tipo de fructíferos acuerdos de cooperación que tengan en cuenta especialmente la situación de los países en desarrollo. En esos acuerdos debería preverse, entre otras cosas,

3 Con la excepción de Perú, España, y quizá Canadá y otros pocos Estados costeros. En esta materia fue imposible mantener la unidad del grupo de Estados costeros. 
el empleo y la capacitación técnica de pescadores nacionales, la transmisión de tecnologia en lo que hace a las artes y métodos de pesca y a la industrialización del producto en plantas nacionales.

\section{La zona económica y el tratamiento global e integrado de los usos del mar}

Se ha procurado describir algunos de los principales problemas a que ha dado lugar la consagración de la zona económica exclusiva y las soluciones que se han encontrado para resolverlos. Debe reconocerse, obviamente, que no son perfectas. Pero para los países en desarrollo a los que en mayor grado interesa establecer un nuevo orden económico internacional, esa respuesta, aún parcial e imperfecta, representa un enorme adelanto. Lo más notable es el hecho mismo de que se haya podido reconocer universalmente, o casi universalmente, la nueva institución de la zona económica exclusiva. Habría que recordar que hace apenas cinco o seis años había una oposición cerrada y firme de las potencias maritimas pesqueras para aceptar esta noción. Representó un alejamiento radical de principios que contaban con varios siglos de existencia. El convenio que surja de la Conferencia de las Naciones Unidas sin duda no dará satisfacción a todos. Pero será un paso importante que tendrá efectos claros y favorables en la situación de los países en desarrollo. Es satisfactorio recordar que México tuvo una participación decisiva en la concepción inicial, en la formulación jurídica y en la aceptación política de esta noción. La primera iniciativa formal presentada ante el Comité Preparatorio de la Conferencia estableciendo la zona económica exclusiva fue presentada conjuntamente por Colombia, México y Venezuela.

Con todo, difícilmente se puede estar satisfecho de los resultados hasta ahora alcanzados. Precisa reconocer sus carencias e imperfecciones. No se puede perder de vista ni abandonar el objetivo de alcanzar en el futuro un régimen que regule el aprovechamiento de los mares y sus recursos en forma más racional, integrada y global. Como antes se dijo, el antiguo principio de la libertad de los mares, en su aspecto de libertad de pesca, está basado en el concepto de que los recursos vivos del mar, antes de su captura, son res nullius. En la actualidad, y más aún en el futuro, simplemente no puede admitirse que una reserva alimenticia esencial para la humanidad sea concebida y explotada como algo que no es de nadie. Esto representa apenas un orden normativo elemental y primario, que sólo se explica en una situación de gran abundancia y escasa demanda, como ocurría en el pasado con los productos del mar. El célebre biólogo Thomas Huxley decía a principios de siglo que la mejor manera de conservar los recursos del mar era explotándolos. Esto fue cierto pero no lo es hoy. Las propias premisas en que Grocio fundaba la libertad de los mares, es decir, el carácter prácticamente ilimitado y la imposibilidad de aprehender el mar, como el aire, 
ya han dejado de ser ciertas. En nuestra época, los recursos del mar, sean renovables o no, el mar libre y su lecho y subsuelo, deben ser considerados como res communes, como bienes que pertenecen a todas las naciones y no a nadie.

Toda la actitud de la humanidad frente al mar tendrá que cambiar. El aumento acelerado de la población mundial y el consiguiente incremento en la demanda de alimentos de origen marino; la creciente industrialización en todos los continentes; la concentración de las poblaciones en las áreas costeras; la extracción cada vez mayor de hidrocarburos en las plataformas continentales; la explotación y procesamientos próximos de los nódulos polimetálicos que yacen en los fondos marinos; el incremento de la navegación y el uso cada vez mayor de grandes petroleros, de transportadores de gas licuado y de embarcaciones de propulsión nuclear; el empleo también creciente de substancias químicas que en elevada proporción terminan en el mar; y los avances acelerados en materia de tecnología pesquera son otras tantas razones que imponen la necesidad de reglamentar globalmente, y administrar internacionalmente, el aprovechamiento de los mares. Cada día surgirán nuevos y mayores conflictos entre los distintos usos competitivos de los océanos, que, por supuesto, ningún país puede resolver solo.

Además, se produce una constante interacción entre los múltiples usos de los mares. La explotación de los recursos del lecho marino puede afectar la utilización de las aguas suprayacentes, y viceversa; las actividades en las zonas internacionales y en las costeras se afectan recíprocamente. El mar en su conjunto y la atmósfera que lo cubre forman un sistema ecológico. Todas estas interacciones exigen una visión y un tratamiento globales $e$ integrados de los ámbitos marinos.

\section{Papel de las organizaciones internacionales}

A ese respecto, las organizaciones internacionales deben desempeñar un papel central y decisivo. Puede preverse que en el futuro se creen nuevas organizaciones regionales que regulen la pesca en distintas partes del mundo. Además, es lógico que las numerosas organizaciones que actualmente existen, adopten nuevas normas para una regulación más efectiva de la pesca, quizá asumiendo funciones regulatorias que en el pasado estaban reservadas a los estados. El impacto de la pesca en las condiciones actuales es global. Lo que ocurra en una región puede afectar a otras. Es indispensable coordinar por ello la acción de las organizaciones regionales. Quizá la manera racional y viable de hacerlo sería integrando esa red de organizaciones dentro de la organización principal, de vocación universal, es decir, la FAo.

Pero no es ese el único problema. Cada vez en mayor grado habrá que coordinar racionalmente los distintos usos competitivos del mar. No se puede regular una actividad sin pensar en las otras. Será indispensable desde 
ahora armonizar esas actividades mediante arreglos institucionales apropiados, es decir, como se le ha llamado, mediante "una maquinaria integrativa", que incluya a diversas organizaciones que tienen que ver con el aprovechamiento del mar y sus recursos. Además de la FAo, estos mecanismos coordinados deben comprender a la Organización Marítima Consultiva Internacional (OCMI), al Comité Oceanográfico Internacional de la UNESCO, a las propias Naciones Unidas y seguramente a otras. Esto podría ser el paso inmediato más importante para una futura administración internacional global de los mares y sus recursos. 